\title{
FORMAÇÃO DE PROFISSIONAIS PARA A EDUCAÇÃO DE JOVENS E ADULTOS NA ÁFRICA SUBSAARIANA: O desafio de um mestrado universitário francófono a distância
}

Stéphanie Gasse ${ }^{(*)}$

Desde 1996, o Departamento de Ciências da Educação da Universidade de Rouen (França) oferece um Mestrado $2^{1}$ profissional intitulado Ofício da formação - arquitetura e orientação em formação, tanto presencial quanto a distância. A partir de 2001, a formação vem sendo realizada no âmbito do consórcio Formação e Recursos em Ciências da Educação (FORSE). O campus digital é constituído por duas universidades francesas (Universidade de Rouen e Universidade de Lyon 2) e pelo Centro National de Ensino a Distância (CNED). Oferecendo ensino a distância em Ciências da Educação na Licenciatura, no Mestrado 1 e, no Mestrado 2 profissional a pesquisa, já permitiu a formação de 12.000 estudantes.

A partir de 2004, firmou-se uma parceria com a Agência Universitária da Francofonia (AUF), junto à qual a formação em Mestrado tem repercussão bastante favorável, sobretudo na África Ocidental francófona. O objetivo do Mestrado - realizado em dois anos - é, assim, formar "especialistas polivalentes do mundo da educação e da formação", de modo multidimensional, que deverá acompanhar o planejamento e desenvolvimento de projetos de educação e formação no domínio das políticas regionais, de recursos humanos ou de mediação educacional (um tipo de educação especializada).

O primeiro ano do Mestrado focaliza, por meio de uma abordagem interdisciplinar, questões sobre educação e formação e faz o acompanhamento pela elaboração de um dossiê exploratório de pesquisa, relacionado com os eixos de pesquisa do Laboratório Centre Interdisciplinaire de Recherches sur les Valeurs, les Idées, les Identités et les Compétences (CIVIIC), da Universidade de Rouen.

\footnotetext{
${ }^{(*)}$ Faculdade de Ciências da Educação, Laboratório CIVIIC na Universidade de Rouen, França. Laureada em 2015-2016 pela Cátedra francesa na UERJ - Pesquisadora Visitante Sênior Internacional pela Embaixada da França no BrasilUERJ. Áreas de pesquisa: Educação de jovens e adultos, Educação não formal, Educação comparada e abordagens internacionais; dispositivos inovadores (Presencial e a distância).

1 O número 2 é uma referência ao segundo ano do Mestrado (Ano 1 Mestrado em Ciências da Educação, Ano 2 Mestrado de pesquisa ou profissional).
} 
O segundo ano do Mestrado, chamado de formação profissional de educadores, oferece especialização com uma oferta curricular baseada em políticas de formação; em concepção de dispositivos de formação; em arquitetura pedagógica; e em um componente essencial da educação permanente: a orientação acadêmica dos indivíduos ou das organizações na lógica de formação ao longo da vida.

De maneira geral, a formação estabelecida pela Faculdade de Ciências da Educação e sua realização questionam em muitos níveis os objetivos iniciais do curso, definidos por:

1. formação de especialistas do mundo da educação e da formação em meios diversificados;

2. contribuição a uma mudança local, a uma ação social, feita por profissionais preocupados em se formar e contribuir ao desenvolvimento, à aplicação e ao reforço de políticas que favoreçam a EJA na África subsaariana;

3. meios implementados na aprendizagem a distância (programa de formação, especificidade do público inscrito, características da equipe docente responsável pela orientação e pelo acompanhamento).

Este artigo posiciona-me em três níveis de intervenção no dispositivo de formação a distância (FORSE) utilizado: como responsável pelo Mestrado a distância; como pedagoga de um dispositivo inovador; e como pesquisadora da área de desenvolvimento de projetos de promoção da EJA e da formação de profissionais deste campo.

A pesquisa tem, por objetivo, questionar especificidades dos estudantes de um determinado território (Burkina Faso, África Subsaariana); e o impacto de uma formação a distância e de práticas de intervenção educativa de profissionais no campo da formação de adultos e nas políticas de EJA, em termos de desenvolvimento local. Para isso, a exposição foi dividida em três partes: inicialmente, a apresentação da formação a distância; em seguida, características dos estudantes inscritos; por último, modalidades pedagógicas implementadas e objetivos fixados; enfim, uma contribuição à reflexão prática e teórica sobre o nível de impacto interno e externo da formação.

\section{UMA FORMAÇÃO INOVADORA IMPLEMENTADA PELAS CIÊNCIAS DA EDUCAÇÃO}

\subsection{A quem atende a formação}

A formação do Mestrado integra-se à oferta de formação da Faculdade de Educação da Universidade de Rouen (Normandia, França), que se inscreve no sistema europeu de L,M,D 
(Licenciatura durante três anos; Mestrado durante dois anos, Doutorado durante três anos) do Processo de Bolonha (1999) para o ensino superior, denominado Promoção da sociedade do conhecimento e da mobilidade internacional.

Essa disposição europeia permite o desenvolvimento da formação e de projetos de alcance internacional destinando-se, assim, à mobilidade estudantil e dos professores.

A Universidade de Rouen acolheu, em 2014, 36.000 estudantes, dos quais 100 no Departamento de Ciências da Educação, dentre os quais $65 \%$ inscritos no contexto da mobilidade a distância. No Mestrado a distância, há 250 estudantes inscritos.

Diante de tal sucesso, as modalidades pedagógicas tiveram de se enriquecer de uma metodologia ativa e de uma equipe reforçada para poder acompanhar o público inscrito. Desde 2004, e após firmada a parceria com a Agência Universitária da Francofonia, um número maior de estudantes vindos da África Subsaariana se inscreveram nesse programa. Mais de 30\% dos estudantes inscritos a distancia vêm de um país estrangeiro - a maioria de países da África Subsaarina e da África do Norte (Burkina Faso, Mali, Camarões, Gana, Nigéria, Mauritânia, Argélia, Marrocos, Egito, Madagascar).

\subsection{Um currículo integrado ao objetivo de reforço de competências}

Como anunciado, o objetivo do Mestrado é preparar especialistas polivalentes (professores, educadores, orientadores pedagógicos) que poderão acompanhar de forma pluridimensional os planejamentos e o desenvolvimento de projetos de educação no campo das políticas territoriais de EJA.

A maioria desses profissionais, no entanto, querem não só obter um diploma qualificado do ensino superior, mas também ampliar suas competências e a perspectiva de evolução profissional no campo da educação e da formação.

A formação a distância se organiza de maneira idêntica à formação presencial, apenas com a especificidade de a modalidade se dar a distância. Isto permite o estabelecimento de um modelo alternativo de disseminação de conhecimentos e de compartilhamento de experiências.

No primeiro ano, o plano de formação compreende cinco unidades de ensino (equivalentes a 450 horas de formação): 
Tabela 1: Plano de formação Master 1 (por títulos e conteúdos do curso)

\begin{tabular}{|c|c|}
\hline $\begin{array}{l}\text { A - Ensino de fundamentos } \\
\text { disciplinares }\end{array}$ & $\begin{array}{l}\text { Filosofia da educação } \\
\text { História: instituições e práticas } \\
\text { Sociologia da educação } \\
\text { Psicologia da educação }\end{array}$ \\
\hline $\begin{array}{l}\text { B - Ensino de fundamentos } \\
\text { pluridisciplinares }\end{array}$ & $\begin{array}{l}\text { Educações e sociedades } \\
\text { Tecnologias da informação e da comunicação }\end{array}$ \\
\hline C - Língua & Língua Inglesa \\
\hline D - Pesquisa em educação e formação & $\begin{array}{l}\text { Metodologia qualitativa } \\
\text { Metodologia quantitativa } \\
\text { Dossiê exploratório de pesquisa }\end{array}$ \\
\hline $\begin{array}{l}\text { E - Opção profissionalizante } \\
\text { (à escolha) }\end{array}$ & $\begin{array}{l}\text { Opção 1: Ofícios da educação escolar e do } \\
\text { entorno da escola } \\
\text { Opção 2: Ofícios da intervenção sanitária e } \\
\text { social } \\
\text { Opção 3: Ofícios da formação de adultos }\end{array}$ \\
\hline
\end{tabular}

Fonte: Ardouin, Daguet, Gasse, Savarieau, 2014.

A opção de profissionalização corresponde a um reforço do conhecimento adquirido pelos estudantes no exercício de suas profissões como professor, como educador especializado ou como especialista em formação de adultos.

O segundo ano do Mestrado é mais profissionalizante e complementado por um estágio (de 3 meses) e por um trabalho de pesquisa (Memorial) chamado de pesquisa-ação.

A formação (450 horas) possibilita o enriquecimento das seguintes competências:

- permitir, aos envolvidos, conhecer processos da arquitetura de formação, o que significa conceber, estabelecer, dirigir, desenvolver e avaliar sistemas de formação;

- aprofundar e dominar referências teóricas desses domínios de intervenção no campo das Ciências da Educação;

- desenvolver um conhecimento e uma cultura da avaliação, na lógica de avaliar para evoluir;

- dirigir uma missão de intervenção, de orientação ou de formação durante o estágio com a metodologia apropriada;

- desenvolver metodologias e conhecimentos científicos dentro da pesquisa (Memorial). 
- No sentido de cumprir as horas de formação e as competências, estabeleceram-se cinco núcleos a elas correspondentes, que se desdobram em disciplinas, o que se pode verificar na Tabela 2, a seguir.

Tabela 2: Plano de formação Master 2 profissional (por títulos e conteúdos do curso)

\begin{tabular}{|c|c|}
\hline $\begin{array}{l}\text { A. Política, sistema e } \\
\text { instituições }\end{array}$ & $\begin{array}{l}\text { Política, instituições, sistema de formação } \\
\text { Sociologia das organizações } \\
\text { Economia da formação } \\
\text { Direitos do trabalho, da formação e dos dispositivos } \\
\text { Abordagens internacionais e educação comparada }\end{array}$ \\
\hline B. Arquitetura de projeto & $\begin{array}{l}\text { Direção de projeto } \\
\text { Planejamento financeiro e marketing da formação } \\
\text { Direção de projeto e iniciativa de qualidade }\end{array}$ \\
\hline C. Arquitetura pedagógica & $\begin{array}{l}\text { Psicologia de adultos em formação } \\
\text { Tecnologia da Informação e Comunicação e Ensino aberto a distância } \\
\text { (FOAD) } \\
\text { Pedagogia e didática em formação } \\
\text { Trabalhos colaborativos, animação de grupos, práticas da formação }\end{array}$ \\
\hline D. Noções de orientação & $\begin{array}{l}\text { Análise do trabalho, de emprego e competência } \\
\text { Orientação em formação } \\
\text { Adultos em formação e acompanhamento de pessoas } \\
\text { Ética na intervenção }\end{array}$ \\
\hline $\begin{array}{l}\text { E. Metodologia e etapas de } \\
\text { projetos }\end{array}$ & $\begin{array}{l}\text { Metodologia qualitativa } \\
\text { Metodologia quantitativa } \\
\text { Memorial de pesquisa } \\
\text { Inglês }\end{array}$ \\
\hline
\end{tabular}

Fonte: Ardouin, Daguet, Gasse, Savarieau, 2014

\subsection{Modalidades pedagógicas e equipe pedagógica reforçada}

Esses diferentes ensinamentos são ministrados por meio de materiais do curso on-line tipo Massiva Online Open Courses (MOOC), ${ }^{2}$ acompanhados de trabalhos colaborativos realizados durante o ano letivo, em grupos de 4-6 estudantes orientados por um professor responsável pela disciplina, quando as aulas virtuais desempenham papel de regulação das aprendizagens. Seminários de acompanhamento a uma pesquisa são dirigidos e coordenados por orientadores de memoriais via Fórum online. Um Fórum geral, animado por uma coordenadora pedagógica permite interação entre estudantes e a equipe pedagógica.

As seguintes ferramentas tecnológicas acompanham a formação e possibilitam o rompimento do isolamento da modalidade a distância:

\footnotetext{
${ }^{2}$ Trata-se de cursos a distância, com a participação ilimitada e acesso livre e aberto.
} 
- Plataforma de formação online - uma plataforma inovadora de e-laringe que disponibiliza cursos online e faz toda a gestão da formação.

- Curso e exercícios (Pdf, vídeoconferência ou palestra, em que o ministrante pode, ou não, incluir uma vertente de interatividade com os outros utilizadores do serviço).

- Trabalho colaborativo para discutir a mesma questão ou resolver o mesmo problema; processos de cooperação para, conjuntamente, resolver um problema e/ou partilhar uma concepção conjunta.

- Aula virtual - fórum de discussão e compartilhamento de documentos. Gerido por um professor com um grupo de estudantes.

- Acompanhamento individual e coletivo (Fórum) - possibilita debates de diversos temas propostos entre membros de um projeto ou de pessoas interessadas em temas específicos; acompanhamento individual professor-estudante.

- Recursos online - revistas, videoconferências, ferramentas metodológicas, software de banco de dados, processamento de dados.

- Wiki - criação de documentos e recursos pelos estudantes, para ser compartilhado.

- Atividades sincrônicas e as sincrônicas - ação interativa entre professor-estudante e estudante-estudante em atividades sincrônicas (p. ex., web conferências, videoconferências e chats); e as sincrônicas (p. ex., fórum, correio eletrônico) realizadas em ambientes virtuais de aprendizagem.

A equipe pedagógica que supervisiona os 250 estudantes inscritos durante os dois anos de formação é composta de professores-pesquisadores do Departamento de Ciências da Educação empenhados na modalidade a distância, mas também conta com uma equipe de tutores, distribuída da seguinte maneira: a) responsável pelo dispositivo de ensino a distância; b) tutores (15); c) equipe administrativa; d) animador da Plataforma online; e) orientadores de pesquisa, autores do curso equipe qualificada de professores doutores com produção científica e experiência profissional na área de educação (25); f) engenheiro / técnico (manutenção online).

Reuniões de pesquisa são organizadas durante três dias, quatro vezes por ano, para trabalhar os objetivos da formação com os estudantes; rever seus projetos pedagógicos e os projetos de pesquisa; e ajudar a manter o ritmo esperado de investimento na formação, diante do esquema intenso que lhes é imposto. 
Considerada a diversidade geográfica dos estudantes, as reuniões/seminários são feitos na Universidade de Rouen e, ao mesmo tempo, nos lugares mais distantes em que estão os parceiros, dentro do Campus digital da África Subsaariana, devidamente organizados pelas demais universidades parceiras da AUF.

O Campus Digital Francófono (CNF) disponibiliza a infraestrutura técnica necessária ao monitoramento dessas formações nos países que necessitam do dispositivo de educação ao longo da vida. Uma atenção particular é dada durante os dois anos de formação para os objetivos seguintes: a) iniciação e formação científica (epistemologia e ferramentas metodológicas); b) trabalho com a noção de projeto em Educação e Docência - estudo de casos; c) enriquecimento dos conhecimentos nas áreas das Ciências da Educação; d) posicionamento crítico sobre a postura e a ética profissional.

Desta forma, o dispositivo educação ao longo da vida mantém-se e se desenvolve continuadamente, em busca crescente de integração. Por isso, as modalidades pedagógicas devem, a todo momento, ser reforçadas pelo conhecimento do público acolhido, de suas motivações e de suas necessidades de formação.

\section{NECESSIDADE DE CONHECIMENTO DO PÚBLICO PARA AJUSTAR AS PRÁTICAS PEDAGÓGICAS E MEDIR O IMPACTO}

\section{Nossa abordagem de pesquisa qualitativa}

A pesquisa realizada em 2014 sobre as seis turmas formadas por estudantes universitários da África Subsaariana de Mestrado em Ciências da Educação da Universidade de Rouen, em formação a distância, trabalha com 48 inscritos (2007-2013 e, em média, 80\% de aprovação. Priorizamos nossa atenção sobre o site remoto Ouagadougou, em Burkina Faso, porque historicamente este país da África Ocidental francófona foi o primeiro a responder a esta oferta de formação de Mestrado a distância. O número de pedidos de integração ao programa está em constante evolução e parece importante para se questionar sobre o público de profissionais de EJA e conhecer as motivações dos estudantes, e de suas necessidades de formação. A particularidade das situações e a singularidade dos casos está no centro de nossas preocupações, na perspectiva de acompanhamento da qualidade na formação superior.

Uma parte da formação é realizada no Campus da Universidade de Ouagadougou e a metodologia inclui duas vertentes:

1. Na primeira, trabalhamos com um questionário qualitativo cujo objetivo é o conhecimento do público selecionado, 48 alunos $(\mathrm{N}=48)$, feito por meio das características apresentadas no momento do ingresso na formação a distância; de suas 
motivações; de seus projetos de formação já realizados (como parte dos estágios de aperfeiçoamento); do impacto causado em suas práticas e expectativas do futuro profissional.

2. Na segunda vertente, organizamos um grupo focal com dez estudantes $(\mathrm{N}=10)$, com o objetivo de aprofundar as problemáticas desenvolvidas durante o projeto de intervenções aplicadas ao desenvolvimento local, no âmbito das missões de estágio realizadas nas instalações, o impacto gerado no desenvolvimento de habilidades coletivas permitindo, assim, começar a pensar sobre as expertises desenvolvidas no interior das instituições.

É preciso levar em conta a existência de certos limites, na medida em que se trabalha sobre nosso próprio sistema de formação a distância, tirando da sombra a proximidade entre a postura de investigador/pesquisador e a de professores responsáveis pelo dispositivo.

\section{PERFIL DOS ESTUDANTES NO INÍCIO E NO FIM DA FORMAÇÃO}

\section{Dos estudantes formados e envolvidos na experiência}

O campo estudado foi composto de 45 estudantes, dos quais $4 / 5$ do sexo masculino. A turma é composta de estudantes oriundos de Burkina Faso (26/48) mas igualmente de estudantes de países fronteiriços e da África central (22/48), por ser o dispositivo a distância, uma ferramenta que facilmente atinge um público geograficamente mais extenso.

A idade média de entrada na formação é de 41 anos, o que nos leva a deduzir que esses estudantes já têm uma experiência profissional juntamente com uma experiência acadêmica, com uma média de 4 a 5 anos de estudos universitários (Ciências Humanas e Sociais, Economia/Direito, Engenharia) e que mais da metade obteve seu diploma em países estrangeiros.

A experiência adquirida na educação e na formação se situa entre 6 e 10 anos. Ao ingressarem na formação, todos os estudantes são assalariados, dos quais 3/4 trabalhando no setor público, atuando no ensino médio/secundário; no técnico e/ou profissional; em empresas privadas (formação de recursos humanos); como consultores independentes ou pertencentes a organizações não governamentais (ONG) e a organizações intergovernamentais (OIG), cuja presença é numerosa nesta região da África Ocidental, sobretudo em políticas educativas descentralizadas. Para estes últimos, podemos destacar como áreas de atuação os setores de desenvolvimento rural; social e da saúde; de educação e formação; e de microfinanças, todas ligadas de uma forma ou outra à educação. 


\section{O QUE REVELA A PESQUISA SOBRE OS ESTUDANTES INSCRITOS}

\section{Alunos motivados}

Quais são as lógicas subjacentes à entrada na formação a distância? Pesquisamos sobre projetos profissionais expressos no momento da entrada na formação. Classificamos os projetos por ordem de importância:

1. Procura interna para responder às exigências da atividade: corresponde a fornecer um suporte à estrutura de pertencimento, reforçando as competências internas.

2. Uma especialização em arquitetura da formação: o argumento avançado aqui é de promover a profissionalização em formação de adultos, pela aquisição de ferramentas, de metodologias reconhecidas no campo para conduzir ações de análise, de concepção, de realização e avaliação de projetos em EJA.

3. reconhecimento de um título universitário de $3^{\circ}$ ciclo: a lógica do Mestrado é privilegiada pelo reconhecimento internacional de um diploma, verdadeiro passaporte para a mobilidade de trabalhadores em agências e instituições de cooperação bilateral (Europa e Nações Unidas) em maioria de origem estrangeira. O reconhecimento do diploma acompanha uma eventual continuação de estudos no doutorado, como $3^{\circ}$ ciclo.

4. Evolução e promoção interna: finalmente, é a promoção interna que se destina à uma evolução para outras missões, em paralelo, de orientação e consultoria.

Por meio desses projetos, o que eles expressam em termos de motivação é primeiramente a aquisição e o reforço de competências, na perspetiva de um reconhecimento profissional para a continuidade dos estudos, com uma evolução prevista de reconversão profissional com a finalidade de um desenvolvimento pessoal.

\section{Alunos inseridos}

A três meses do fim da formação, entre os estudantes diplomados, $40 \%$ ainda estão posicionados no mesmo emprego mas com um avanço em suas missões. Um percentual de $47 \%$ se beneficia de uma promoção interna para cargos de chefia e conseguem uma evolução salarial.

Dos estudantes pesquisados, um aparece inscrito em um organismo de busca de emprego depois do fim do contrato de trabalho antecipado e buscava evoluir para o cargo de formador consultivo independente. Finalmente, $40 \%$ dos estudantes se envolvem com a criação de empreendimentos (oficina de estudos, consultoria em formação) por tempo completo ou como um segundo emprego, mantendo seu trabalho principal assalariado. 
Como resultado da formação, mais de $2 / 3$ se envolvem na continuação de estudos do Mestrado, na perspectiva de um Doutorado. Um percentual de 27\% prepara-se para concurso, visando sair da situação contratual na função pública ou para integrar uma organização internacional.

Passado um ano da formação, 76\% dos egressos consideram que seu emprego está diretamente relacionado com a formação seguida e, sobretudo, com o projeto inicial.

\section{OBJETIVOS DA FORMAÇÃO: PROJETOS PROFISSIONALIZANTES CONTEXTUALIZADOS}

Os estudantes se inscrevem na lógica pedagógica do Mestrado no momento da realização do estágio: a) em termos de duração, em média o fazem por mais de 12 semanas, podendo chegar até de 16 a 28 semanas; b) em termos de diversidade dos setores de atividades: Serviço de Formação de adultos do setor público ou privado; Formação Profissional Continuada em empresa ou em estabelecimento público; em Instituto Universitário de Formação de Professores; em Saúde pública e educação (ações de sensibilização com populações, programas de saúde pública); c) ou, ainda, em tipos de missões como: serviços de auditoria; de orientação e apoio ao desenvolvimento de empresas; avaliação e reestruturação de ofertas de formação; evolução para a integração de Tecnologias de Informação e Comunicação na Educação (TICE).

As problemáticas de pesquisa nas quais investem esses estudantes nos levam a acompanhar os memoriais sobre o desenvolvimento e integração de uma abordagem de arquitetura da formação; a motivação para entrar em processo de formação; a eficiência e a eficácia das ações de formação; o desenvolvimento de novas tecnologias aplicadas à educação; a análise dos circuitos de financiamento e de estudos prospectivos.

Estes diferentes aspectos testemunham a vontade de profissionalização com o reforço efetivo das competências em modelagem e consultoria de formação. Os problemas de pesquisa são realizados internamente, no ambiente de trabalho do estudante $(73 \%)$ ou fora das instituições de origem, por $27 \%$.

\section{CONTRIBUIÇÃO A UMA REFLEX̃̃O PRÁTICA E TEÓRICA SOBRE O IMPACTO INTERNO E EXTERNO DA FORMAÇÃO}

A partir dessa pesquisa contextualizada, circunscrita a Burkina Faso, e da nossa experiência adquirida no uso do dispositivo a distância desde sua criação, podem-se localizar três níveis de impacto na formação. 


\section{Impacto da formação em termos de modelagem e de estratégia pedagógica}

A modelagem pedagógica baseia-se no princípio de mesclagem:

$\checkmark$ mesclagem das situações de formação: formação presencial e a distância; conferências por profissionais; seminário de trabalho em grupo; formação na/e para a vida profissional (um estágio / uma missão / um tutor). A formação individualizada proposta se organiza no interesse da convergência entre ferramentas teóricas e metodológicas, projeto pessoal e práticas profissionais (estudos de caso, memoriais).

$\checkmark$ mesclagem de conhecimentos: meio profissional / pesquisa. A circulação das práticas, das técnicas e dos conhecimentos na arquitetura da formação se constrói pela mediação entre o mundo da pesquisa e o das organizações. $O$ conjunto de conhecimentos se apóia no curso das aulas em que se confrontam, em função das temáticas da atualidade; dos pontos de vista dos professores do Mestrado; dos conferencistas (pesquisadores, profissionais); e dos estudantes.

$\checkmark$ mesclagem de intervenientes: além dos professores universitários, os estudantes podem também se apoiar nas redes profissionais e em outras fontes de recursos.

$\checkmark$ mesclagem de estudantes: o recrutamento dos estudantes de origens diversas visa a promover a confrontação de pontos de vista e criar elementos de transversalidade. Esta heterogeneidade (assalariados, estudantes, formação inicial, formação continuada, experiências diversas, públicos, zonas geográficas, estruturas diferentes...) é desejada e permite aos estudantes confrontar suas redes, suas lógicas e seus saberes. O grupo e a forma como ele é conduzido pretende também ser instrumento de aprendizagem.

A formação no Mestrado é baseada em uma estratégia pedagógica concertada e testada por praticantes-teóricos. Com efeito, a formação em uma perspectiva individual pode ser descrita a partir de quatro funções (ARDOUIN, DAGUET, GASSE, SAVARIEAU, 2014):

$\checkmark$ uma função de elaboração $e$ formalização do projeto: a abordagem de individualização da formação está ligada a esta primeira função que é a de ajudar à emergência de um projeto de formação coerente. Nesse ponto, estamos no nível de um "currículo de formação" no qual, dados os objetivos do demandante e de suas possibilidades, determina-se uma estratégia de formação.

$\checkmark$ uma função de acompanhamento: os agrupamentos visam essencialmente a reduzir a distância entre o que o estudante realiza efetivamente e o que é esperado dele. 
Paralelamente, ele é seguido por um orientador de memorial durante sua realização. Cabe ao estudante interpelar este e planejar as diferentes etapas, estas favorecendo duas modalidades da pedagogia ativa, a saber: a individualização do percurso mas também a autonomia da aprendizagem.

$\checkmark$ uma função formação: a formação baseia-se na oferta de recursos educativos que são os módulos de formação, as reuniões de pesquisa presenciais e o guia. A função formação se apoia também na coletivização de boas práticas e no apoio do grupo. Cada um traz seus conhecimentos e sua experiência como suportes para o grupo.

$\checkmark$ uma função reconhecimento/certificação da aprendizagem em três níveis: o reconhecimento das aquisições resultantes da experiência e da qualificação, indo além do objetivo formação. O reconhecimento das aquisições pode ser considerado como uma abordagem de emergência e de apropriação pelo estudante de suas próprias capacidades. Em segundo lugar, uma avaliação formativa como um elemento de manejo da formação pelo estudante em relação aos professores. Finalmente, a avaliação somativa que conclui a formação e verifica a qualificação obtida de maneira normatizada e regulada.

\section{O IMPACTO DA FORMAÇÃO NO DESENVOLVIMENTO LOCAL ENDÓGENO}

O objeto da investigação também observa igualmente o impacto da formação de Mestrado a distância no desenvolvimento de um território, pela posição dos estudantes como atores da interface entre, de um lado, beneficiários diretos do projeto e ações de formação e, do outro, as instituições. Como constatamos anteriormente, pelo estudo de objetivos da formação, a realização de um projeto profissional e o acompanhamento à reflexão que acompanha, contribui ao desenvolvimento das competências no interior dos projetos profissionais contextualizados e acordados nos lugares de estágio, respondendo assim a um problema localizado.

Esses projetos de formação contribuem para desinvisibilizar o desenvolvimento local, endógeno e participativo, ambiente favorável ao desenvolvimento da expertise num dado território, a partir desta fórmula iniciada por Bachelard (1993): "é o meio que molda a percepção do homem"3․

O desenvolvimento local participativo é visto aqui como uma vontade de render operacionalidade a ações entre atores interessados em trabalhar em projetos engajados em um ambiente imediato (DENIEUIL, 2005). O conceito de desenvolvimento local aparece em um

\footnotetext{
${ }^{3}$ Tradução livre de: "c'est le milieu qui façonne la perception de l'homme".
} 
contexto crítico de visão centralizadora do Estado e de iniciativas desenvolvidas em nível global sem repercussão local. No fim dos anos 1950 o desenvolvimento endógeno descrevia uma abordagem voluntarista que o concebia como abordagem vinda do local, privilegiando recursos endógenos. (GASSE, ARDOUIN, 2015)

A abordagem participativa insiste na responsabilização das populações por meio do conceito de conscientização, popularizada pelo pedagogo brasileiro, teórico da ação educativa, Paulo Freire e, mais particularmente, na sua obra Pedagogia do oprimido (FREIRE, 1974). Freire (1974) referese ao conceito de consciência crítica como ferramenta educativa sociopolítica que envolve o aprendiz e o incita a se questionar sobre a origem de sua situação histórica e social, que o autor interpreta como ler o mundo. O objetivo da consciência crítica, de acordo com Freire (1974), trata de criar um sujeito para uma sociedade democrática.

As abordagens participativas são objeto de paixão às vezes exploradas e instrumentalizadas pelas agências internacionais, pela nova ordem educacional mundial, privilegiando intenções de princípio a engajamentos voluntários de descentralização e de desconcentração sobre as estruturas locais. Entre as principais limitações dessa perspectiva, está o fato de que a abordagem muitas vezes se resume a simples "diálogos" participativos, a trocas ritualizadas em que os atores locais só validam, ou melhor, alimentam as análises e escolhas feitas por agentes externos. Com efeito, a ambiguidade constitutiva do conceito de "participativo" especifica a presença obrigatória e central de uma intervenção exógena, na qual participam os atores locais. Esta situação é pouco adaptada para o surgimento de dinâmicas endógenas de decisão e de planejamento. A autonomia dos atores locais está longe de ser completa, seja na formulação de problemas, na escolha de prioridades ou na tomada de decisões. Ora, o princípio da endogeneidade consiste em transformar o ator local em decisor local, cuja regra é que o acompanhamento técnico não determine nenhum objetivo antes de sua abordagem, ou que este objetivo seja fruto de uma decisão acordada sobre o território.

O planejamento territorial é, antes de tudo, uma obra política e não técnica, o que significa que, diante da incerteza do futuro, a responsabilidade de escolha, antes de tudo política e ética, deve ser deixada aos responsáveis políticos legítimos, conforme o princípio de uma democracia representativa, e às populações, conforme à democracia participativa. Burkina Faso desenvolve, desde 2007, uma política de descentralização da educação e da formação sobre agências e instituições, redes de parcerias, ainda que sobre regiões, comunidades, coletividades locais, no âmbito de uma política de desconcentração.

Somente uma dinâmica endógena será capaz de sustentar e se multiplicar a um nível razoável sem apoio externo pesado e permanente. Tem por objetivo a instalação de um processo 
local e coletivo de tomada de decisão (uma descentralização razoavelmente orquestrada e desconcentração sobre as regiões, com o apoio e participação das comunidades). A relação de assistência, de soberania alternativa, de ajuda sob condições... alterna-se para uma relação de parceria contratualizada (reconhecimento mútuo), baseada no reconhecimento de saberes, percepções e legitimidade dos atores locais.

O conceito situa-se na base da maioria dos métodos e das ferramentas utilizadas nas últimas décadas para apoiar o desenvolvimento. Em nosso contexto de formação de Mestrado a distância na ótica profissionalizante, as missões assinaladas demonstram um tempo de projeto imediato (GASSE, 2008), com o objetivo a longo prazo de reforçar o desenvolvimento de um território, em um contexto em que a descentralização das agências e das instituições aparece como verdadeira causa para o fato de o Estado não toma suficientemente a seu cargo a missão educativa e nem faz dela uma prioridade.

A análise de indicadores macroeconômicos e sociais de Burkina Faso mostra que a problemática da EJA se põe sobretudo em relação a acesso, a eficiência, a pertinência, a qualidade e a adaptação das ofertas de formação, segundo necessidades econômicas e socioculturais das populações. Burkina Faso ainda enfrenta um desafio demográfico significativo. Situado no coração da África ocidental, o país conta com mais de 15 milhões de habitantes. O crescimento demográfico é de 3,4\% ao ano. Mais de $70 \%$ da população tem menos de 35 anos. Na população, 72\% não sabe ler nem escrever em uma língua. O Artigo 34 da Constituição de Burkina Faso reconhece o francês como língua oficial, que é apenas a língua administrativa. A esta se acrescentam, na entrada no sistema educativo, três línguas nacionais faladas por $70 \%$ da população sobre sessenta línguas identificadas em mais de sessenta etnias.

Em nível econômico, dois setores são responsáveis pelo crescimento. Trata-se do setor agrossilvopastoril e o setor de artesanato. O setor agrossilvopastoril participa com 32\% do PIB (agricultura 17\%, criação 12\%). Este setor assegura emprego e renda a $85 \%$ da população ativa. Constitui o primeiro provedor de emprego no país.

A demanda de formação é grande para o desenvolvimento local endógeno, uma perenização de transmissão de saber-fazer que ultrapassa bastante a necessidade de formação de base por via da alfabetização funcional. Em todos os níveis do sistema educativo, Burkina Faso está comprometido com a evolução de reformas educativas, apoiadas por uma infinidade de atores do setor formal e não formal, cuja coordenação inexiste, para pôr, em andamento operacional, projetos de acordo com os beneficiários das ações. 
O país engajado na alfabetização funcional, em grande parte por uma política descentralizada e baseada na educação não formal, sofre com o empobrecimento das estruturas educativas regidas pelo Estado em termos de formação de professores - de formação continuada dos profissionais do setor.

\section{O IMPACTO EM TERMOS DE PROFISSIONALIZAÇÃO NO SETOR DE EJA EM UM DETERMINADO TERRITÓRIO}

Duas constatações relevantes se impõem neste artigo, decorrentes da pesquisa realizada: primeiramente, a aceitação da profissionalização fundamentada em conhecimentos do setor de EJA. De fato, a profissionalização dos sujeitos e das estruturas é questionada em três formas de interação: sociológica (ROCHE, 1999); individual (HEBRARD, 2004) e pedagógica (WITTORSKI, ARDOUIN, 2012).

$\mathrm{Na}$ dimensão sociológica, a profissionalização é o caminho obrigatório de passagem da condição de ocupação para o status de profissão, passando assim pelo reconhecimento da profissão. Nossos estudantes puseram em evidência o reforço de sua autonomia e o pertencimento a uma categoria de atores, cujo reconhecimento social se traduz por uma inserção mais ampla e também maior visibilidade da profissão na sociedade. O nível ético e a percepção de prestação de serviço à comunidade é um elemento marcante dos projetos educativos desenvolvidos e apresentados durante a formação dos estudantes. A profissionalização, neste sentido, é uma construção social que se estabelece em confronto e posicionamento diante de outros ofícios e profissões. A profissionalização busca, desta forma, marcar seu território e ser reconhecida pela sociedade em geral.

Na dimensão individual, a profissionalização é o desenvolvimento do saber-fazer em qualificação, em competência, quer dizer, em profissionalidade. Assim, o curso de Mestrado tem, por ambição, dotar, confrontar e confirmar os saberes e competências dos atores da educação e da formação, por via de cursos, de metodologias e de realizações práticas e profissionais.

Enfim, em sua dimensão pedagógica, a profissionalização adere à vontade de disponibilizar uma formação "mais profisssional" em três aspectos distintos:

$\checkmark$ inscrever a experiência dos aprendentes no centro da formação; como suporte à reflexão em um ambiente socioeconômico específico, e no reforço das aprendizagens; 
$\checkmark$ afastar-se e distanciar-se das experiências vividas via exploração de dimensões teóricas e metodológicas adquiridas ao longo da formação;

$\checkmark$ adaptar e preparar o público em formação com vista à sua inscrição no emprego em relação e com o meio socioeconômico e cultural. Por esta razão o estágio e a missão que dele decorre são elementos privilegiados da formação, como escolhidos pelos alunos inscritos no Mestrado.

Sendo assim, falar de profissionalização é questionar-se sobre ambos estes aspectos ou a combinação dos três que são, de fato, ligados e ao mesmo tempo interdependentes neste "jogo de configurações" (ELIAS, 1987). Os sujeitos desenvolvem, por conseguinte, uma profissionalidade reconhecida, podendo ser obtida pela ligação entre a formação profissional e uma prática exigente e distanciada.

A segunda constatação - a expertise em tensão - evidencia que os estudantes estagiários são atores ligados ao sistema (às instituições que eles representam) e ao meio em que vivem (beneficiários dos projetos e das iniciativas desenvolvidas). A dinâmica participativa os incita (de forma voluntária eles se reúnem em seus territórios para pensar o futuro) e os promove, reforçando suas posturas e visibilidade como especialistas. Um número significativo de estudantes se encaminham, de forma paralela, às funções de ensino e de formação, em instituições públicas e privadas, atuando como consultores independentes. A missão desses profissionais não se limita ao viés educativo mas vai mais além: buscam a defesa de ações de sensibilização nos setores como da saúde e do social, para o desenvolvimento local endógeno, que permita sair da extrema pobreza, e abrindo acesso a uma educação de qualidade para todos e ao longo da vida. São testemunhas destes avanços uma parte importante de professores, educadores e formadores inscritos neste Mestrado. Profissionais estes que trabalham em instituições públicas e igualmente em organizações da sociedade civil ou em organizações não governamentais, em contato direto com as comunidades.

Por consequência, além do número elevado de estudantes inscritos nas formações a distância de nível Mestrado, a particularidade das situações e a singularidade dos casos nos impõem, como professores pesquisadores, a acompanhar um público de estudantes motivados, formados e, sobretudo, experientes, em busca de reconhecimento profissional de suas missões de EJA. Esta constatação é ainda mais forte entre estudantes oriundos de países em que as políticas educativas estão inseridas em contextos não centralizados, dissipados em diversas regiões e comunidades locais, tais como Burkina Faso, país escolhido como exemplo na pesquisa. 
O dispositivo é enriquecido por este público com múltiplas demandas, e nos obriga a uma adaptação da oferta de formação em termos de conteúdo e, também, ao acompanhamento da modalidade a distância, com métodos pedagógicos flexíveis, inovadores e alternativos, a fim de reforçar práticas profissionais e inseri-los em processos de profissionalização e de postura de prática reflexiva.

Segundo Schön (1983, p. 26): "O desafio é reabilitar a razão prática, o conhecimento sobre ação e da experiência, a intuição, a expertise baseada em um diálogo com a realidade e de reflexão na ação e sobre a ação, isto é, a prática reflexiva. ${ }^{4}$

Assim, como praticante pensante, o profissional formado utiliza a reflexão "sobre e na" ação, com o objetivo de resolver os problemas de situações profissionais com capacidade de análise e de compreensão do ambiente e dos públicos beneficiários, ao mesmo tempo em que desenvolve competências e reforça sua postura nas missões educativas.

\section{REFERENCIAS ${ }^{5}$}

ARDOUIN, Thierry. L'éducation non formelle: des mondes sociaux à l'ingénierie du développement. In: Education permanente. n. 199, p. 39-48, 2014.

ARDOUIN, D.; GASSE, S. Guides pédagogiques de l'étudiant en formation de Master à distance (Master1 et Master2). Université de Rouen, Campus Numérique FORSE/ CNED/ AUF, 2014.

BACHELARD, Gaston. Les acteurs du développement local. Paris: L’Harmattan, 1993.

DENIEUIL, P-J. Introduction aux théories et à quelques pratiques du développement local et territorial. Genève: Bureau International du Travail, 2005.

ELIAS, Norbert. La société des individus. Paris: Fayard, 1987.

FREIRE, Paulo. Pédagogie des opprimés. Paris: Maspéro, 1974.

GASSE, Stéphanie. Education non formelle et apprentissages tout au long de la vie. Education permanente. n. 199. Paris: CNAM, Juin, 2014.

La dynamique partenariale en contexte décentralisé: une conception de l'ingénierie au sein de l'expertise éducationnelle. In: ARDOUIN, T.; CLENET J. (Dir.). L'ingénierie de la formation: questions et transformations. Transformations. n. 5, juin, 2011.

Education non formelle, quel avenir? Regard sur le Mali. Thèse Doctorat au Education) - Université de Rouen (France), Rouen, 2008.

; ARDOUIN, Thierry. Um mestrado francófono a distância para a formação de profissionais da educação em Burkina Faso. Revista Científica e-Curriculum. <http://revistas.pucsp.br/index.php/curriculum/issue/view/1524>. Acesso: 20 abr. 2016.

HEBRARD, P. Formation et professionnalisation des travailleurs sociaux, formateurs et cadres de santé. Paris: L'Harmattan, 2004.

\footnotetext{
${ }^{4}$ Tradução livre para « L'enjeu est donc de réhabiliter la raison pratique, les savoirs d'action et d'expérience, l'intuition, l'expertise fondée sur un dialogue avec le réel et la réflexion dans l'action et sur l'action, c'est-à-dire la pratique réflexive ».
} 
PROCESSO DE BOLONHA. Cooperação interuniversitária de reconhecimento de diplomas. Disp.: <http://www.coe.int/t/dg4/highereducation/EHEA2010/BolognaPedestrians_fr.asp>. Acesso: 20 abr. 2016.

ROCHE, J. Que faut-il entendre par professionnalisation? In: Education permanente, n. 140, p. 35-49, 1999.

SCHÖN, Donald A. The reflexive practitioner. How Professionals Think in Action. États Unis: Basic Book Inc. Trad. fr., Le praticien réflexif, Montréal: Les Éditions Logiques, 1985.

WITTORSKI R., A. Thierry. La professionnalisation: étudier la complexité des liens sujet-organisation. In: CLÉNET, J., MAUBANT, P., POISSON, D. Formations et professionnalisations: à l'épreuve de la complexité. Paris: L'Harmattan, 2012.

\section{Sites}

AUF - Agence Universitaire de la Francophonie: <www.auf.org>.

CNED - Centre National d'Enseignement à Distance: <www.cned.fr〉.

FORSE - Formation et Ressources en Sciences de l'Education: <www.sciencedu.org>. 


\title{
RESUMO
}

A proposta de formação em Ciências da Educação (Sciences de l'Education) da Universidade de Rouen (França) inclui, desde 1996, um Mestrado Profissional em Educação que trabalha com a formação continuada de professores para a Educação de Jovens e Adultos (EJA). O aumento da demanda de formação, sobretudo a distância, levou a Universidade de Rouen a desenvolver relevantes parcerias, com o objetivo de ampliar a oferta de vagas para a formação e de reforçar os dispositivos existentes. Desde 2004, uma parceria foi firmada com a Agência Universitária da Francofonia (AUF) junto à qual a proposta do Mestrado tem repercussão bastante favorável, sobretudo no Oeste da África francófona, o que possibilitou a disponibilização de bolsas de estudos e a abertura para um novo público, tratando de novas problemáticas de formação de professores. O objetivo do Mestrado profissional é preparar especialistas polivalentes (professores, educadores) que poderão acompanhar de forma pluridimensional os planejamentos e o desenvolvimento de projetos de educação no campo das políticas territoriais de EJA. Este artigo pretende, a partir da perspectiva da responsável pedagógica, apresentar o Mestrado a distância no contexto da África subsaariana e suas especificidades tanto em relação ao público atendido como também à equipe que o acompanha.

Palavras-chave: mestrado profissional; África subsaariana francófona; formação continuada de professores a distância

\section{PROFESSIONAL TRAINING FOR YOUTH AND ADULT EDUCATION IN SUB- SAHARAN AFRICA: THE CHALLENGE OF A MASTER'S DEGREE IN DISTANCE LEARNING}

\begin{abstract}
The curriculum in Educational Sciences (Sciences de l'Education) at the University of Rouen (France) includes, from 1996 a professional Master's degree of education working with the continuing education of teachers for young people and adult education (EJA). The increase in demand for training, especially in distance, led the University of Rouen to develop relevant partnerships in order to expand the supply of places for training and to enhance existing devices. Since 2004, a partnership was established with the Agence Universitaire de la Francophonie (AUF) where the proposed Master has favorable repercussions, especially in the West Francophone Africa, which allowed the provision of scholarships and an opening to a new audience, dealing with new problems of teacher training. The aim of the professional Master is to prepare polyvalent experts (teachers, educators) who can monitor the planning and development of educational projects in the field of territorial EJA policies in a multi-dimensional way. This article, from the perspective of a pedagogical supervisor, aims to present the Master in distance learning in the context of sub-Saharan Africa and its specificity both for the public served as well as the team that accompanies it.
\end{abstract}

Keywords: professional master's degree ; french-speaking sub-Saharan Africa; continuing education in distance learning.

Submetido em Jan. 2016 Aprovado em Jun. 2016 